\title{
Ecohydrology in Mediterranean areas: a numerical model to describe growing seasons out of phase with precipitations
}

\author{
D. Pumo, F. Viola, and L. V. Noto \\ Dipartimento di Ingegneria Idraulica ed Applicazioni Ambientali, Univ. of Palermo, Viale delle Scienze, 90128 Palermo, Italy
}

Received: 3 August 2007 - Published in Hydrol. Earth Syst. Sci. Discuss.: 4 September 2007

Revised: 17 December 2007 - Accepted: 26 January 2008 - Published: 27 February 2008

\begin{abstract}
The probabilistic description of soil moisture dynamics is a relatively new topic in hydrology. The most common ecohydrological models start from a stochastic differential equation describing the soil water balance, where the unknown quantity, the soil moisture, depends both on spaces and time. Most of the solutions existing in literature are obtained in a probabilistic framework and under steady-state condition; even if this last condition allows the analytical handling of the problem, it has considerably simplified the same problem by subtracting generalities from it.

The steady-state hypothesis, appears perfectly applicable in arid and semiarid climatic areas like those of African's or middle American's savannas, but it seems to be no more valid in areas with Mediterranean climate, where, notoriously, the wet season foregoes the growing season, recharging water into the soil. This moisture stored at the beginning of the growing season (known as soil moisture initial condition) has a great importance, especially for deep-rooted vegetation, by enabling survival in absence of rainfalls during the growing season and, however, keeping the water stress low during the first period of the same season.

The aim of this paper is to analyze the soil moisture dynamics using a simple non-steady numerical ecohydrological model. The numerical model here proposed is able to reproduce soil moisture probability density function, obtained analytically in previous studies for different climates and soils in steady-state conditions; consequently it can be used to compute both the soil moisture time-profile and the vegetation static water stress time-profile in non-steady conditions.

Here the differences between the steady-analytical and the non-steady numerical probability density functions are analyzed, showing how the proposed numerical model is able to capture the effects of winter recharge on the soil moisture.
\end{abstract}

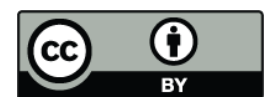

Correspondence to: D. Pumo (pumo@idra.unipa.it)
The dynamic water stress is also numerically evaluated, implicitly taking into account the soil moisture condition at the beginning of the growing season. It is also shown the role of different annual climatic parameterizations on the soil moisture probability density function and on the vegetation water stress evaluation.

The proposed model is applied to a case study characteristic of Mediterranean climate: the watershed of Eleuterio in Sicily (Italy).

\section{Introduction}

The ecohydrology may be defined as that branch of hydrology that seeks to describe the hydrologic mechanisms underling ecologic pattern and processes. During last years several ecohydrological models have been developed and improved, different each other and characterized by different goals. Most of the existing ecohydrological models are based on a soil water balance, even if some differences are present in the model components and in the solving approaches.

In order to derive an analytical solution of the soil water balance, Rodriguez-Iturbe et al. (1999a) developed a model based on a simplified scheme; this model allows to study the soil moisture temporal dynamics in water controlled ecosystems, and provides a simplified realistic description of the interactions between climate, vegetation and soil. This kind of approach is the starting point for a quantitative evaluation of the soil moisture effects on ecosystems dynamics and of the vegetation response to water stress. It is also useful in the study of the hydrological control on the nutrient cycles into the soil and in the study on the competition dynamics for water among the various species (Rodriguez-Iturbe and Porporato, 2004). Laio et al. (2001b) obtained the analytical expression for the soil moisture probably density function $(p d f)$ in steady state conditions. This model has been applied in regions where the growing season is usually in phase with

Published by Copernicus Publications on behalf of the European Geosciences Union. 
the wet one (Laio et al., 2001a). These climatic conditions make the steady-state hypothesis reasonably satisfied, since the effects of the transient condition, due to an initial soil moisture condition (at the beginning of the growing season), are limited to a short time-period.

In scientific literature there are only few studies regarding climates with temperature and rainfall seasonally out of phase. Kiang (2002) and Baldocchi et al. (2004) analyzed the stochastic soil moisture dynamics and the related water stress for a Californian savanna, where the climate is semi-arid and similar to Mediterranean. Using soil moisture data recorded in situ, Kiang (2002) compared these data with the predictions of the stochastic model proposed by Laio et al. (2001b), finding a general good agreement but with some differences due to the role of the initial soil moisture transient, not included by the analytic model.

For Mediterranean climates, the steady-state hypothesis during the growing season is not valid because the transient effects of high initial soil moisture conditions are not negligible, especially for deep-rooted vegetation. For this type of climate, the precipitations are mainly concentrated in the October-March period, when the vegetation is almost inactive. For this reason, during the wet season the level of soil moisture tends to increase, and it will be available for the vegetation at the beginning of the subsequent growing season (from April to September). The vegetation, adapting itself to these soil moisture dynamics, often develops an extensive water uptake strategy, by delving the roots into the soil in order to utilize the water stored in the deeper layers.

With regard to the link between the soil moisture and the vegetation response, low soil moisture level implies a reduction in plants physiological capacities, and if the reduction of soil moisture is severe or prolonged, it may cause permanent damages to the vegetation. Porporato et al. (2001) suggest a method for water stress quantification, defining the static water stress and the dynamic water stress under the above mentioned hypothesis of steady state condition. The static water stress $\zeta$ gives a static description of physiological effects induced by water stress. In the above definition, the incipient stomatal closure is related to the soil moisture value $s^{*}$, below which it is assumed that the water stress increases. Transpiration and root water uptake continue at a reduced rate until soil moisture reaches the wilting point $s_{w}$, below which the plant suffers a permanent damage that quickly leads plant to the death. The resistance mechanism to the soil moisture deficit adopted by plants is closely related to water stress duration. If the water stress is characterized by a short duration, the vegetation does not suffer any damages, while, when the same stress remains for longer, the wilting phase takes over, with permanent damages for the plants that become unable to re-establish their own vital functions. For these reasons it is necessary to consider also the length of the intervals in which vegetation is under stress and the number of such intervals during the growing season in order to characterize properly the vegetation water stress. The dynamic water stress $\theta$ ex- plicitly considers the mean duration and frequency of water stress periods.

Starting from the Laio et al. (2001a) model, here a new approach is proposed, in order to reproduce the soil moisture dynamics in Mediterranean climate during the whole hydrologic year. This approach uses a numerical model which implicitly takes into account the transient effects of the initial soil moisture condition at the beginning of the growing season and works using an opportune time-scale (lower than daily), through a finite differences method, computing the soil moisture temporal evolution.

The soil moisture dynamics, reproduced through this numerical model, summarize the interrelationships among climate, soil and vegetation and furthermore are strongly correlated with the vegetation stress, defined by Porporato et al. (2001). In particular, the static water stress is numerically computed from the soil moisture time-profile. Starting from the same profile it is also possible to calculate the mean duration and frequency of water stress periods and hence a dynamic water stress index.

The model shown in this paper, is applied at the forested Eleuterio river basin in Sicily (Italy) with the purpose to show this different kind of approach to ecohydrological models in Mediterranean areas, investigating also the influence of different annual discretizations of the model parameters on the results.

\section{The analytical and the numerical approaches}

\subsection{Soil water balance at a point and the analytical solution}

Rodriguez-Iturbe et al. (1999a) considered the water balance vertically averaged over the root zone, under the simplifying assumption that the lateral water contributions, mainly due to topographic effects, can be neglected. The soil water balance equation is a stochastic ordinary differential equation, describing at each point the behavior of soil moisture in time, by linking climatic, pedological and vegetational features. It is constituted by a deterministic part given from the distribution of water fluxes within the soil (infiltration, evapotranspiration and leakage), and by a stochastic part given from the nature of the precipitation.

The form of the water balance equation here considered is the following (Rodriguez-Iturbe et al., 2004):

$n \cdot Z_{r} \cdot \frac{d s}{d t}=\varphi(s, t)-\chi(s, t)$

where $n$ is the soil porosity and $Z_{r}$ is the rooting depth (theirs product is the active soil depth $n Z_{r}$ ), $s$ is the relative soil moisture content, $\varphi(s, t)$ is the rate of infiltration from rainfall (taking into account the amount of water lost through canopy interception $\Delta(t)$ and through runoff $Q(s, t))$, and $\chi(s)$ is the water losses from the soil (due to evapotranspiration $E(s, t)$ and leakage $L(s, t))$. The equation does not have any particular time-scale. 
Working at the spatial scale of a few meters and at the temporal scale of the growing season, the rainfall input may be considered as an external forcing, independent of soil moisture state. Therefore, rainfall depth is assumed to be an independent random variable exponential distributed with mean value $\alpha$, while the occurrence of rainfall is assumed to be a marked stationary Poisson process with rate $\lambda$ (RodriguezIturbe et al., 2004).

The vegetation intercepts part of the rainfall, which never arrives to soil surface and is lost directly through evaporation. Interception is incorporated in the stochastic model by fixing a threshold for rainfall depth $\Delta$, below which no water reaches the ground, while for rainfall depth higher than $\Delta$, the water arriving to soil surface is equal to theirs difference.

All the others terms of the balance are considered using the same notation of Rodriguez-Iturbe et al. (2004). Figure 1 shows the assumed scheme for the soil water losses and, in particular, the dependence of $\chi(s)$ by the relative soil moisture content, considering two different values for $E T_{\max }$; the former is a mean value of potential evapotranspiration during the growing season for a typical Mediterranean climate, while the latter is a mean value during the dormant season for the same climate.

The solution of the Eq. (1) consists in the determination of the soil moisture $p d f$ that, in general, depends on time. Assuming that the soil moisture $p d f$ is not time dependent, it is possible to obtain the approximate analytical solution of water balance equation given in Laio et al. (2001b).

\subsection{Numerical solution of the soil water balance}

In the above section, the analytical solution in steady state condition has been shortly discussed. As mentioned in the introduction, it is difficult to find steady-state condition in Mediterranean areas since the soil moisture at the beginning of the growing season is higher than the average of the same period, generating a transient dynamic. In order to overcome the limitation implicitly related to the analytical formulation, the soil moisture $p d f$ during the growing season can be evaluated solving the soil water balance, through a finite differences method. It is possible to estimate the relative soil moisture content $s_{i+1}$ at the time $t_{i+1}$, starting from its value $s_{i}$ at the time $t_{i}$ using the following balance equation:

$\Delta s=s_{i+1}-s_{i}=\left(\frac{\varphi_{i}}{n \cdot Z_{r}}-\frac{\chi_{i}}{n \cdot Z_{r}}\right) \cdot \Delta t$

where $\Delta t$ is the temporal step, while $\varphi_{i}$ and $\chi_{i}$ are the infiltration and the losses, both referred to the time $t_{i}$.

No interaction between the active soil layer and the water table are considered. Moreover it is assumed that the effects on the soil surface driven by raindrop impact (i.e. soil crusting, sealing, etc.) are neglected, and that the porosity $n$ depends only on soil texture, while the rooting-deep $Z_{r}$ depends only on vegetation type, and both are time invariant.

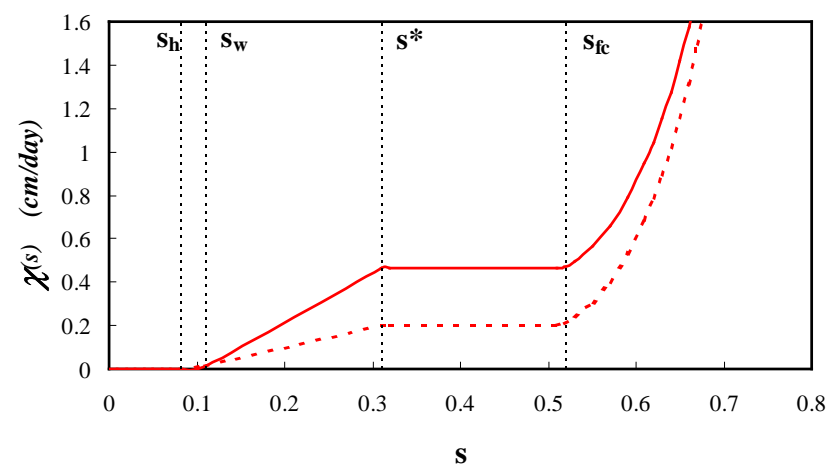

Fig. 1. Soil water losses $\chi(s)$ as a function of relative soil moisture in a loamy sand soil (with features in Table 2). The solid line is referred to a value of $E T_{\max }=0.464 \mathrm{~cm} /$ day while the dashed line considers $E T_{\max }=0.203 \mathrm{~cm} /$ day $($ cf. Table 5$) . E_{w}=0.01 \mathrm{~cm} /$ day.

The model works at a spatial scale of few meters, considering homogenous soil and vegetation.

The seasonal climate variability is represented through a partitioning of the hydrologic year (annual discretization) in several periods with fixed climatic forcing (precipitation and evapotranspiration). The proposed approach could be applied using a simple distinction between the growing (dry) and the dormant (wet) seasons, for which only two sets of parameters, for the rainfall and the evapotranspiration description, are needed. Otherwise it could be applied using a monthly discretization: this kind of representation requires the estimation of twelve mean values of rainfall intensity, rainfall frequency and maximum evapotranspiration rate. All these input data, available at daily time scale, must be aggregated in order to obtain the seasonal or monthly parameters.

Another crucial point for the proposed numerical approach concerns the choice of the temporal discretization $\Delta t$; the importance of this aspect in the numerical estimate of the soil moisture $p d f$ has been tested, evaluating, with different $\Delta t$, the ability of the proposed numerical model in reproducing the analytic soil moisture $p d f$ in steady conditions proposed by Laio et al. (2001b). The agreement between the $p d f$ arising from the two different approaches has been verified using the Pearson's chi-square test. In particular, through an iterative procedure, the minimum $\Delta t$ required for a good fit between the analytical and the numerical $p d f$ has been calculated. Figure 2 shows as different soils and rainfall conditions require different temporal discretizations, while different tests have pointed out that the influence of the rooting depth is negligible.

The key point explaining the behavior of Fig. 2 is the relation between the rain and the leakage losses. When the relative soil water content is higher than field capacity $s_{f c}$, the active soil depth tends to lose water excess by gravity. The loss rate is assumed to be at the maximum $\left(k_{s}=\right.$ saturated hydraulic conductivity) when the soil is saturated and then rapidly decays as the soil dries following the decrease 


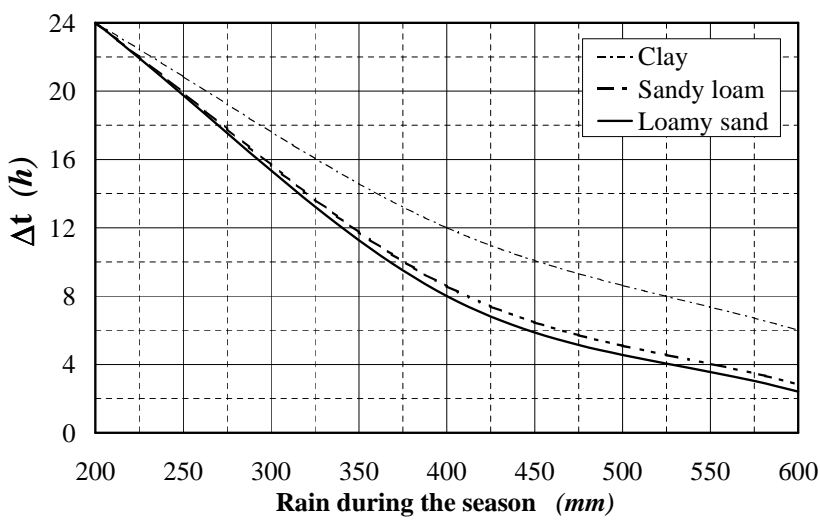

Fig. 2. Minimum temporal discretization needed for a satisfactory reproduction of the analytic soil moisture $p d f(\alpha=1.5 \mathrm{~cm}$; $Z_{r}=90 \mathrm{~cm} ; E T_{\max }=4.64 \mathrm{~mm} /$ day, $T_{\text {seas }}=214$ days; the soils parameters from Table 2).

of hydraulic conductivity $K(s)$. For soil moisture equal to field capacity condition, hydraulic conductivity can be assumed equal to zero. The decay of the hydraulic conductivity is usually modelled using empirical relationships. Here, the exponential form (Rodriguez-Iturbe and Porporato, 2004) has been considered, using a coefficient $\beta=2 b+4$, where $b$ is an index related to the type of soil and pore size. Then the leakage losses functions have been considered with a non linear behavior (as it is shown in Fig. 1 for $s \geq s_{f c}$ ) and they are characterized by $k_{s}, \beta$ and $s_{f c}$ relative to each soil type.

High rates of rainfall imply a higher probability of wet soil conditions and thus the activation of leakage mechanism. The numerical estimation of these leakage losses is very sensitive to the temporal discretization. Particularly, a wide time-step $\Delta t$ leads to an overestimation of leakage contributions; this may be due to the non linear behavior of the used leakage loss equation (Manfreda et al., 2005). Consequently, for assigned soil type, as the rainfall input increases the time-step should be shorter. Keeping constant the rainfall, it is instead possible to observe a relation between the soil parameters (the saturated hydraulic conductivity $k_{s}$ and the exponent of leakage losses equation $\beta$ ) and the values of $\Delta t$ : highly permeable soils with low values of $\beta$ (i.e. loamy sand, $\left.k_{s}=100 \mathrm{~cm} / \mathrm{d}, \beta=12.7\right)$ require lower $\Delta t$.

As shown in Fig. 2, it is possible to reach a satisfactory reproduction of steady state analytical solution in semi-arid or dry climate (less than $300 \mathrm{~mm}$ of rainfall in the considered season) with $\Delta t=12 \mathrm{~h}$ (two steps for day) for all the soil types, while for wet seasons (more than $500 \mathrm{~mm}$ ) $\Delta t$ should be lower for the loamy sand soil $(4 \mathrm{~h})$ and higher for the clay $(8 \mathrm{~h})$. On the other hand, a lower time-step implies a higher computational effort, often not negligible. Obliviously, after that $\Delta t$ has been chosen, it is necessary to reduce all the input data and parameters at the same time-scale.
Once the soil water balance equation has been solved using the finite differences method, the soil moisture time profile is obtained and it is possible to estimate the vegetation water stress following the methodology below described.

\subsection{Indexes of plant water stress}

Moisture reduction into the active soil layer leads to a decrease of plant water potential and consequently of transpiration, potentially dangerous for plant physiological functions.

Under steady state hypothesis, it is possible to calculate the static water stress $\zeta$ introduced by Porporato et al. (2001). This index is equal to zero (minimum value) when the relative soil water content is equal or above $s^{*}$ (incipient stomatal closure), while when $s$ is equal or below $s_{w}$, the stress is equal to one (maximum value). Thus, the static water stress can be expressed as

$\zeta(s)=\left[\frac{s^{*}-s(t)}{s^{*}-s_{w}}\right]^{q}$ for $s_{w} \leq s \leq s^{*}$

where the exponent $q$ takes into account the non-linearity of the relationship between water stress and soil moisture, and its value depends on vegetation species and soil type.

The $p d f$ of static stress $p(\zeta)$ can be analytically obtained from the soil moisture $p d f$. Also the mean value of the static water stress $\langle\zeta\rangle$ can be analytically obtained, by integration, taking into account the second atom of probability (at $\zeta=1)$ through the cumulate probability of having maximum stress $P(\zeta=1)$.

Actually it is more helpful to estimate the mean static water stress on the periods of growing season in which the water stress is really present, neglecting the periods in which $\zeta=0$ (i.e. the static water stress modified $\left\langle\zeta^{\prime}\right\rangle$ ). In order to analytically obtain this last index, the following expression can be used (Porporato et al., 2001):

$\left\langle\zeta^{\prime}\right\rangle=\frac{\langle\zeta\rangle}{P\left(s^{*}\right)}$

where $P\left(s^{*}\right)$ is the value of cumulative distribution of soil moisture calculated in $s=s^{*}$. The static water stress modified $\left\langle\zeta^{\prime}>\right.$ takes into account the mean intensity of water deficit, but it does not contain information on its duration and frequency.

Another index for the evaluation of plant water stress under steady state condition is the dynamic water stress, which also takes into account the crossing properties.

According to Porporato et al. (2001) this index is a water stress measure able to combine, through the variables $\left\langle T_{S^{*}}\right\rangle$ and $\left\langle n_{s^{*}}\right\rangle$, the above defined mean static stress modified $\left\langle\zeta^{\prime}\right\rangle$ with the mean duration and frequency of water stress. $<T_{s^{*}}>$ is defined as the mean duration of stress periods during the growing season, while $<n_{s^{*}}>$ is the number of stress periods during a growing season (mean number of downcrossing or mean number of the soil moisture excursions below $s^{*}$ ). 
According to Porporato et al. (2001), the mean total dynamic stress during the growing season $<\theta>$ can be expressed by a function in which the number $<n_{s^{*}}>$ appears as an exponent and moreover it is in turn raised to the power of $-r$, where $r$ is a constant (according to the authors $r$ is equal to 0.5 ):

$$
\langle\theta\rangle=\left\{\begin{array}{cl}
\left(\frac{\left\langle\zeta^{\prime}\right\rangle \cdot\left\langle T_{s^{*}}\right\rangle}{k \cdot T_{\text {seas }}}\right)^{\left\langle n_{s^{*}}\right\rangle^{-r}} & \text { if.. }\left\langle\zeta^{\prime}\right\rangle\left\langle T_{s^{*}}\right\rangle<k \cdot T_{\text {seas }} \\
1 & \text { if.. }\left\langle\zeta^{\prime}\right\rangle\left\langle T_{s^{*}}\right\rangle \geq k \cdot T_{\text {seas }}
\end{array}\right.
$$

where $k$ is an index of plant resistance to water stress.

The plant response in terms of dynamic water stress, depends on the active soil depth $Z_{r}$. Deep-rooted species (e.g. trees) rely on the winter water recharge into the soil, as opposed to shallow-rooted species (e.g. grasses) that quickly respond to the intermittent rainfall (Rodriguez-Iturbe et al., 2001).

Also this dynamic water stress definition is referred to steady-state conditions. Thus, whenever a not negligible transient period is present this definition is not valid. For example the Mediterranean climate, where the presence of a winter recharge creates a transient in the soil moisture dynamics (whose duration depends mainly on the active soil depth $Z_{r}$ ), is a typical case of not applicability of this kind of approach since it would lead to overestimation of the water stress.

Moreover, using an analytical approach, some of the terms involved in the dynamic water stress formulation may assume physically unrealistic values; e.g. the value of $\left\langle T_{s^{*}}\right\rangle$ is not bounded to $T_{\text {seas }}$ and it is hence possible to have a mean duration of stress periods during the growing season higher than the duration of the growing season.

In order to overcome these limitations, a numerically estimation of the dynamic water stress is proposed and explained in the next section.

\subsection{Numerical evaluation of the vegetation water stress}

Once the soil water balance equation has been solved by finite differences method obtaining the soil moisture timeprofile, it is possible to evaluate the vegetation response in terms of water stress. Through the Eq. (3) the static water stress time-profile is obtained. It is also possible to calculate, during the growing season, the mean static water stress modified. The seasonal values of the number of periods with stress and theirs mean duration can be assessed year-by-year. Averaging the seasonal data on the whole number of simulated years, it is possible to evaluate the mean values for soil moisture $\langle s\rangle$, for static water stress $\langle\zeta\rangle$ and static water stress modified $\left\langle\zeta^{\prime}>\right.$, and finally for the variables $n_{s^{*}}$ and $T_{S^{*}}$ described in the previous section; the evaluation of these variables allows the estimation of the mean dynamic water stress according to Eq. (5). It is important to point out that the main differences between the proposed approach and the analytical one are that in the former the variables $n_{s^{*}}$ and $T_{s^{*}}$ are numerically computed and for this reason they are bounded, that so it is impossible to have values of $T_{S^{*}}$ higher than $T_{\text {seas. }}$. Also the evaluation of the mean static water stress is different, since it is not obtained from the static stress $p d f$ but it is evaluated starting from the soil moisture time-profile, step-by-step evaluating the static water stress by the Eq. (3) and averaging all the results. Similarly the mean static water stress modified is not obtained by the Eq. (4) but simply averaging year by year the static water stress only on the periods in which $\langle\zeta\rangle$ is different from zero and then evaluating the mean value using the entire simulated series.

Even if the two indexes given by Porporato et al. (2001) are defined for steady state conditions, the proposed approach for their numerical estimation provides a complete description of the plants water stress also in presence of a not negligible transient period.

\section{Application}

\subsection{The Eleuterio river basin}

The aim of the following application is to show how to use the model and what results it is able to provide working on a single area, homogeneous in terms of climate, soil and vegetation. The application is also an attempt to investigate on the importance of the annual discretization of the rainfall parameters and the values of the potential evapotranspiration.

The watershed studied in the present study is located near Palermo (Sicily, Italy), at latitude $37.53^{\circ}$. In ancient time this area, near the town of Ficuzza, was a royal hunting reserve, and also for this reason, is nowadays well conserved, with few anthropic actions. The watershed of Eleuterio has an extent of almost $9.5 \mathrm{~km}^{2}$ and its elevation ranges from $517.5 \mathrm{~m}$ a.s.l. to $1635.5 \mathrm{~m}$ a.s.l. with a mean elevation of $792.2 \mathrm{~m}$ a.s.l. and standard deviation of $194.6 \mathrm{~m}$. The watershed is within the "Bosco della Ficuzza" wood. The natural reserve of "Bosco della Ficuzza" with an extent of 5333 ha represents one of the widest natural reserves in Sicily. The present vegetation is mainly of woody type, constituted by Quercus pubescens, Acer campestre and Fraxinus ornus.

The watershed presents a low variability of total annual precipitation and being an ecosystem in an ecological state of maturity, it is also characterized by a low variability in time from pedological and vegetational point of view. Moreover, no interaction between soil and water table is taken into account, since of the deep groundwater observed in the area.

The studied area is constituted by several river channels merging into the Scanzano reservoir (Fig. 3). Three maps of the Eleuterio area (Map of Cultures, Hydrogeological Map, Geological Map), produced in a previous study (Liguori et al., 1983), have been taken into account in determining spatial patterns of soil texture and vegetation. 


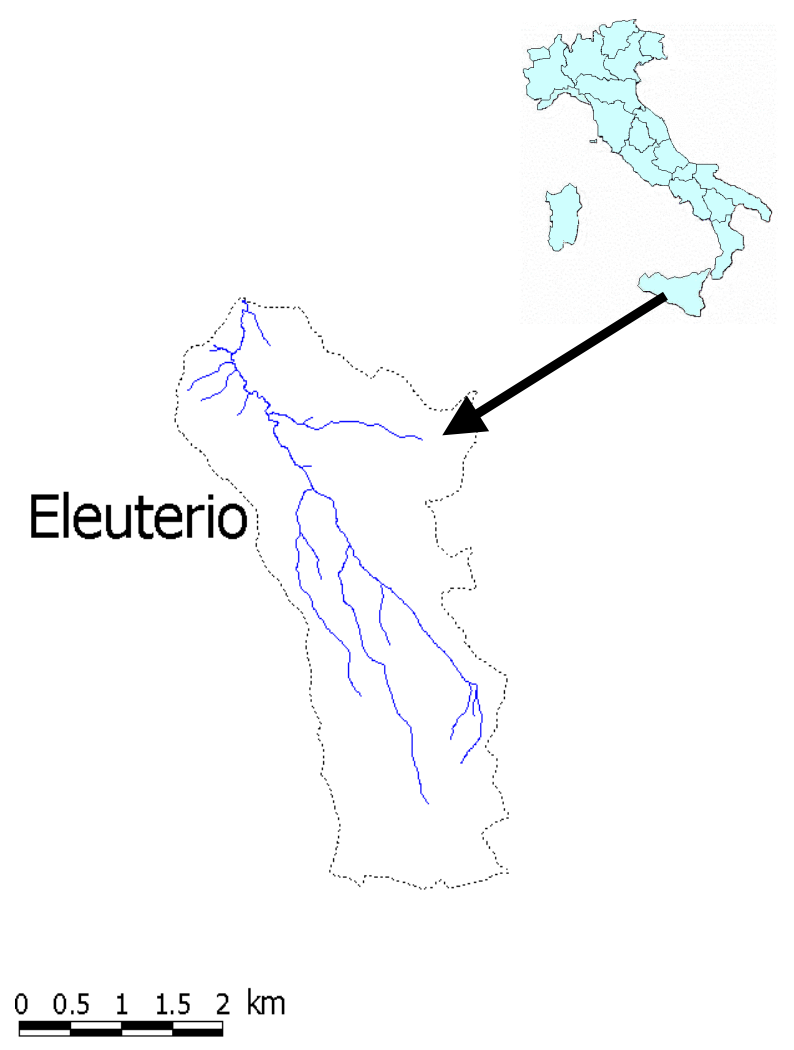

Fig. 3. Location of the Eleuterio basin (Sicily-Italy). In blu are highlighted the main river channels.

The Map of Cultures shows that there is an overriding presence of woody vegetation, even if vineyard, olive tree grove and pastureland with shrub vegetation are also present as well as a low percentage of dry seminative land and bare soils.

From this map it has been derived a vegetational pattern that considers three types of vegetation: trees (areas classified as woody, degraded woody, reforestation zone); shrubs (vineyard, olive tree grove and pastureland); and finally grasses (seminative and sterile). This classification differs from the classical definition of tree, shrub or grass species, because it is based on the deepness of vegetational root-apparatus. The vegetational parameters related to trees are shown in Table 1, using data coming from Caylor et al. (2005).

The Hydrogeological Map and the Geological Map show that the zone of interest is mainly constituted by lithologicaltechnical complexes classifiable as incoherent soil materials in the southern part, pseudo-coherent soil materials in the middle part of the basin and coherent soil materials with pseudo-coherent levels in the northern part and in the eastern one. The information arising from these maps has allowed to recognize three soil types (according to USDA classification) within the basin: sandy loam, loamy sand, and clay. The soils features are summarized in the Table 2.
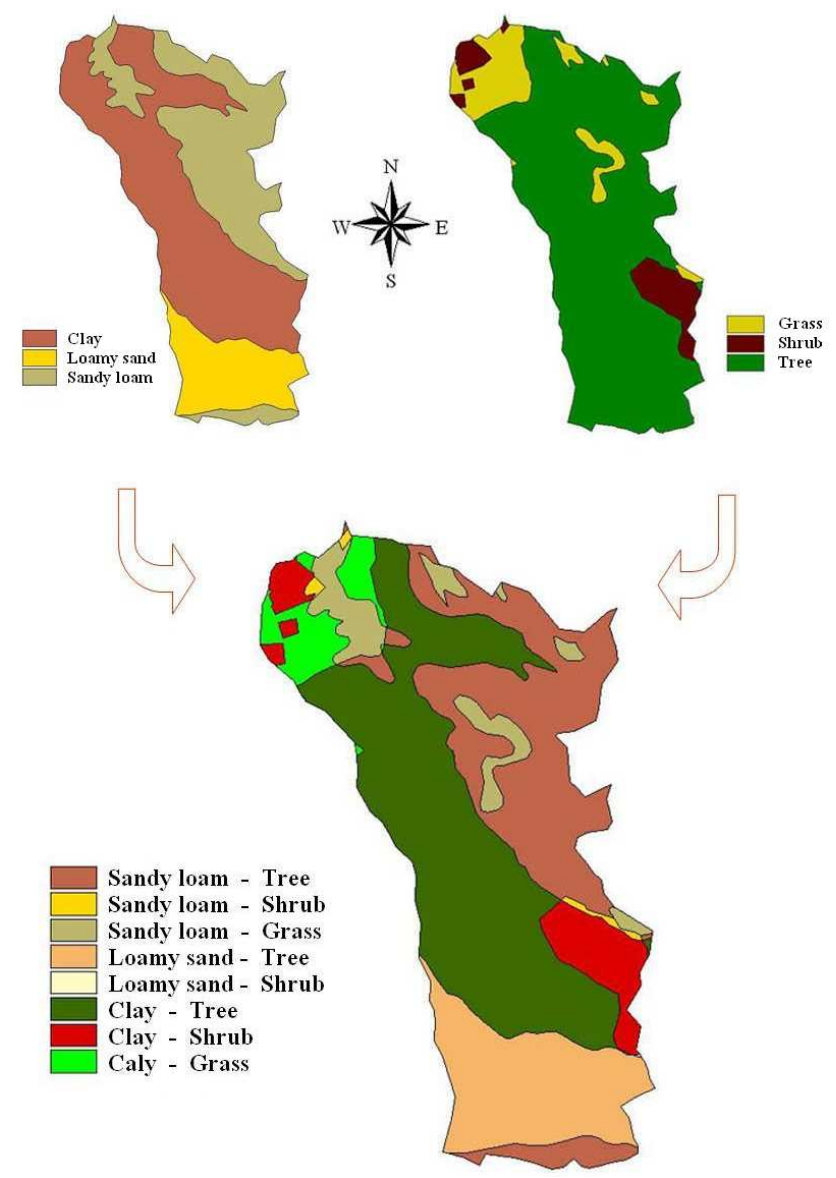

Fig. 4. Spatial pattern of soil texture (top left) and vegetation (top right) for the Eleuterio river basin and theirs spatial overlay (at bottom).

The Fig. 4 shows the vegetational and soil information on the Eleuterio river basin, used in order to obtain the spatial patterns of vegetation and soil; finally the spatial overlay between these layer points out that eight of the nine possible different combinations of soil-vegetation are present within the basin.

Nevertheless, the model has been only applied to the areas covered by trees because the primary aim of this paper is to investigate on the possibility to overcome the problems connected to the transient effect due to a not neglectable soil moisture initial condition in Mediterranean areas. From this point of view, the most critical vegetation cover is certainly the woody vegetation because it is the most subjected to the transient effect (Laio et al., 2001c; Caylor et al., 2005). Particularly, the presence of higher active soil depth causes the increasing of water that can be stored into the soil during the dormancy season, and the dry processes for these deep soils are slower; as consequence of these aspects, more time is required to reach a stationary condition during the growing season. For this reason the application has been limited to a unique vegetation type (that is also the most present within 
Table 1. Parameters describing the vegetation characteristics used in the model application (Eleuterio).

\begin{tabular}{lcccccc}
\hline & $\begin{array}{c}\text { rooting } \\
\text { depth }\end{array}$ & $\begin{array}{c}\text { threshold of canopy } \\
\text { interception }\end{array}$ & $\begin{array}{c}\text { vegetation } \\
\text { height }\end{array}$ & $\begin{array}{c}\text { shortwave } \\
\text { albedo }\end{array}$ & $\begin{array}{c}\text { leaf area } \\
\text { index }\end{array}$ & $\begin{array}{c}\text { maximum stomatal } \\
\text { conductance }\end{array}$ \\
\hline Vegetation type & $\begin{array}{c}Z_{r} \\
(\mathrm{~cm})\end{array}$ & $\begin{array}{c}h_{\Delta} \\
(\mathrm{cm})\end{array}$ & $\begin{array}{c}\mathrm{H} \\
(\mathrm{m})\end{array}$ & $\alpha_{s}$ & $\begin{array}{c}\mathrm{LAI} \\
\left(\mathrm{m}^{2} / \mathrm{m}^{2}\right)\end{array}$ & $\begin{array}{c}g_{s, \max } \\
(\mathrm{m} / \mathrm{s})\end{array}$ \\
\hline Tree & 150 & 0.2 & 4 & 0.1 & 1.5 & 0.01 \\
\hline
\end{tabular}

Caylor et al. (2005) - "On the coupled geomorphological and ecohydrological organization of river basins" - Advances in Water Resources

Table 2. Parameters describing the soil characteristics used in the model application (Eleuterio).

\begin{tabular}{lccccccc}
\hline & $\begin{array}{c}\text { coefficient of the hydraulic } \\
\text { conductivity power law }\end{array}$ & $\begin{array}{c}\text { saturated hydraulic } \\
\text { conductivity }\end{array}$ & porosity & \multicolumn{3}{c}{$\begin{array}{c}\text { characteristic values of } \\
\text { relative soil moisture }\end{array}$} \\
\hline Soil type & $\beta$ & $\begin{array}{c}k_{s} \\
\mathrm{~cm} / \mathrm{d}\end{array}$ & $n$ & $s_{h}$ & $s_{w}$ & $s^{*}$ & $s_{f c}$ \\
\hline Loamy sand & 12.7 & 100 & 0.42 & 0.08 & 0.11 & 0.31 & 0.52 \\
Sandy loam & 13.8 & 80 & 0.43 & 0.14 & 0.18 & 0.46 & 0.56 \\
Clay & 26.8 & 2.5 & 0.5 & 0.47 & 0.52 & 0.78 & 0.91 \\
\hline
\end{tabular}

Laio et al. (2001) - "Plants in water-controlled ecosystems: active role in hydrological processes and responce to water stress" - Advances in Water Resources

the basin), investigating also on the importance of different soil types (sandy loam, loamy sand and clay).

\subsection{Evapotranspiration estimation}

It is assumed that the growing season, in the study area and for the considered vegetation, starts at the beginning of April and finishes at the end of October, with duration of 214 days.

The evapotranspiration at minimum rate $E_{w}$, in correspondence to the wilting point $s_{w}$, can be fixed at value $0.1 \mathrm{~mm} /$ day (Rodriguez-Iturbe et al., 1999b).

In order to estimate potential evaporation, the monthly time series of air relative humidity, heliophany and wind speed have been used because of the difficulty to find daily data series.

Monthly time series of the above mentioned variables have been extracted from records of the Ficuzza gauge station (Atlante climatografico della Sicilia, Regione Siciliana; Augi, 2003). Table 3 shows some meteo-climatic features within the basin; it points out that the maximum values of mean monthly temperatures and air humidity have been observed during the growing season.

Potential evapotranspiration has been estimated by Penman-Monteith method, following a procedure similar to that of Caylor et al. (2005) in which, however, the spatial distribution of climatic variables has not been taken into account because of low spatial variability of these within the watershed. Some of the parameters useful for the evaluation of the potential evapotranspiration are reported in Table 1.
Table 3. Meteo-climatic data for the Eleuterio river basin. $\rho$ and $C_{p}$ are the density and the specific heat capacity of air, respectively; $T_{\max }$ and $T_{\min }$ are the mean daily values of maximum and minimum temperatures respectively; $\mathrm{RH}_{\text {mean }}$ is the avarage daily air humidity.

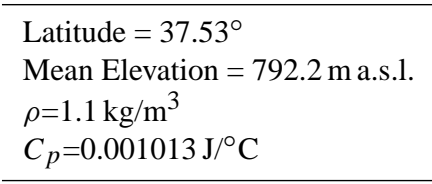

\begin{tabular}{lccc} 
& \multicolumn{2}{c}{ Temperature $\left({ }^{\circ} \mathrm{C}\right)$} & Avarage air humidity $(\%)$ \\
\hline Month & $T_{\max }$ & $T_{\min }$ & $\mathrm{RH}_{\text {mean }}$ \\
\hline Januauy & 11.7 & 3.8 & 69 \\
February & 12.3 & 3.9 & 68 \\
March & 15.0 & 5.2 & 73 \\
April & 18.3 & 7.1 & 74 \\
May & 22.9 & 10.6 & 73 \\
June & 28.5 & 13.7 & 72 \\
July & 31.8 & 16.6 & 73 \\
August & 32.6 & 17.3 & 74 \\
September & 28.2 & 14.9 & 76 \\
October & 22.6 & 12.0 & 75 \\
November & 17.2 & 8.2 & 74 \\
December & 13.3 & 5.1 & 71 \\
\hline
\end{tabular}


(a)

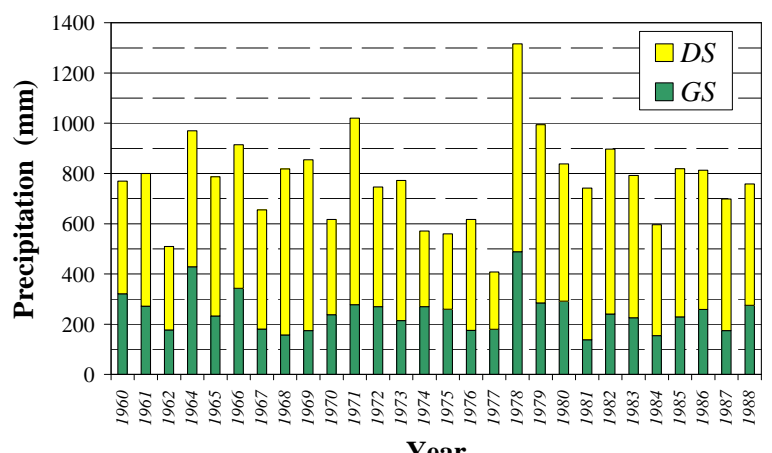

(b)

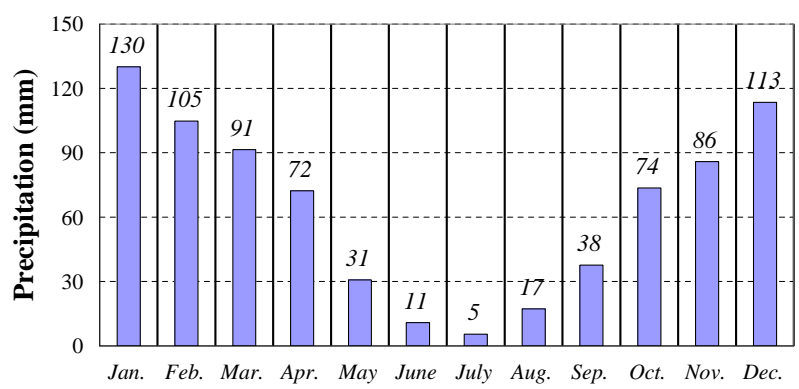

Fig. 5. Eleuterio river basin. (a) Historical rainfall series (from Ficuzza raingauge, 1960-1988). In yellow the precipitation during the dormant season (DS) while in green that during the growing season (GS). (b) Mean monthly precipitations.

\subsection{Schematization of climatic variability}

Figure $5 \mathrm{a}$ and $\mathrm{b}$ represent the recorded precipitation in the Eleuterio river basin. The former shows the annual precipitations during the observation period, divided into precipitation during growing season (green) and that during dormant season (yellow), while the latter shows the mean monthly precipitations. The mean annual precipitation observed is $773 \mathrm{~mm}$, (526 mm during the dormant season). A strong seasonality is evident in monthly precipitation, with higher and more frequent rainfall events during the winter months (in December, January and February over $100 \mathrm{~mm}$ of monthly precipitation) and only $5 \mathrm{~mm}$ of mean monthly rainfall in July.

In order to analyze the effects of a different schematization of the year, two different schemes have been considered: SCHEME A and SCHEME B.

In the SCHEME A, the year is divided into two seasons, the growing season (GS) and the dormant season (DS), each one with its own values of $\alpha$ and $\lambda$ for the precipitations and $E T_{\max }$ for the evapotranspiration, time-invariant (during the season and also year by year), quantities representative of the two seasons. (a)

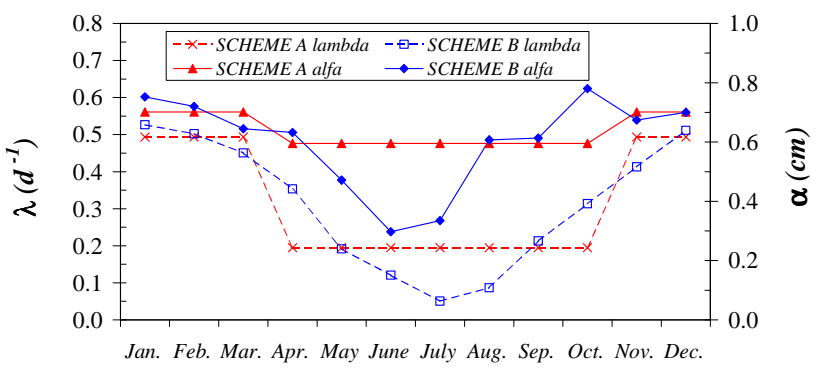

(b)

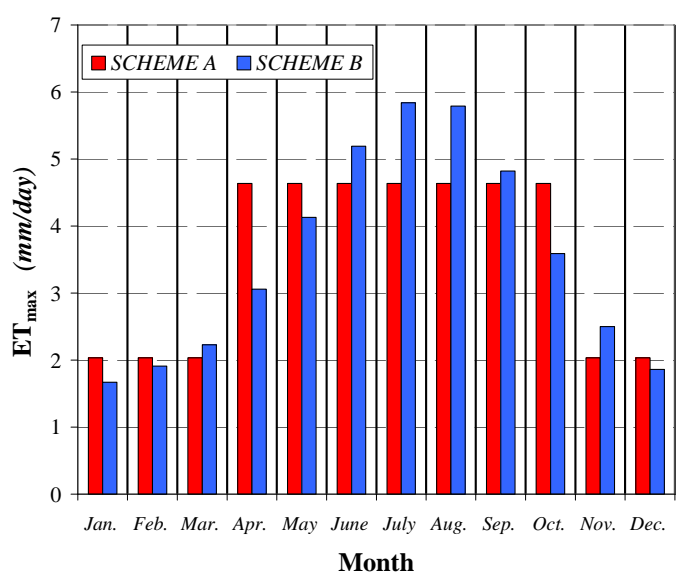

Fig. 6. Eleuterio river basin. (a) Annual fluctuation of the mean seasonal (SCHEME A) and monthly (SCHEME B) values of $\alpha(\mathrm{cm})$ and $\lambda$ (1/day). (b) Annual fluctuations of the mean monthly $E T_{\max }$ $(\mathrm{mm} /$ day) used in SCHEME A and SCHEME B.

In the SCHEME $\mathrm{B}$, the sets of parameters $\alpha, \lambda$ and $E T_{\max }$ are assumed to be time-invariant quantities at monthly timescale, so twelve sets of these parameters are present.

Starting from the historical data series, the seasonal values of $\alpha$ and $\lambda$ (useful for SCHEME A) and the monthly values (useful for SCHEME B) have been derived (Table 4). In the SCHEME A, $\alpha$ and $\lambda$ are constant during each season and are equal to $5.95 \mathrm{~mm}$ and $0.1951 /$ day respectively during the growing season, and $7.01 \mathrm{~mm}$ and 0.4931 /day during the dormant season. In the SCHEME B $\alpha$ ranges from $2.97 \mathrm{~mm}$ (June) to $7.80 \mathrm{~mm}$ (October), while $\lambda$ ranges from 0.051 1/day (July) to $0.1281 /$ day (February).

Similarly, starting from the data shown in Tables 1 and 3, the seasonal and monthly values of $E T_{\max }$ for the woody component of vegetation have been obtained and reported in Table 5. Here it is possible to point out high values of evapotranspiration during the entire summer period with a maximum in July $(5.84 \mathrm{~mm} /$ day $)$.

The different annual fluctuations of the three parameters $\alpha, \lambda$ and $E T_{\max }$ used in the two schemes are emphasized in Fig. $6 a$ and $b$. 
Table 4. In the upper part seasonal and annual values of $\alpha, \lambda$ and the total amount of rainfall $\Theta$ for the Eleuterio river basin. At bottom, mean monthly values and standard deviation (S.D.) (GS = growing season; DS = dormant season).

\begin{tabular}{lcccc}
\hline & $\begin{array}{c}T \\
\text { days }\end{array}$ & $\begin{array}{c}\alpha \\
\mathrm{mm}\end{array}$ & $\begin{array}{c}\lambda \\
1 / \text { day }\end{array}$ & $\begin{array}{c}\Theta=\alpha \lambda T \\
\mathrm{~mm}\end{array}$ \\
\hline GS & 214 & 5.95 & 0.195 & 248 \\
DS & 154 & 7.01 & 0.493 & 526 \\
Annual & 365 & 6.63 & 0.319 & 773 \\
\hline
\end{tabular}

\begin{tabular}{lcccccc}
\hline & \multicolumn{2}{c}{$\alpha$ mean rainfall depth } & \multicolumn{2}{c}{$\lambda=$ mean time between two events } & \multicolumn{2}{c}{ Monthly Precipitation } \\
& Mean & S.D. & Mean & S.D. & Mean & S.D. \\
\hline Month & $\mathrm{mm}$ & $\mathrm{mm}$ & 1 day & $1 /$ day & $\mathrm{mm}$ & $\mathrm{mm}$ \\
\hline Januauy & 7.52 & 2.25 & 0.526 & 0.109 & 130 & 58 \\
February & 7.20 & 1.90 & 0.502 & 0.128 & 105 & 41 \\
March & 6.45 & 2.34 & 0.45 & 0.123 & 91 & 42 \\
April & 6.32 & 3.17 & 0.354 & 0.100 & 72 & 48 \\
May & 4.71 & 2.75 & 0.191 & 0.076 & 31 & 23 \\
June & 2.97 & 2.37 & 0.12 & 0.056 & 11 & 10 \\
July & 3.35 & 2.40 & 0.051 & 0.053 & 5 & 7 \\
August & 6.07 & 4.52 & 0.086 & 0.053 & 17 & 18 \\
September & 6.14 & 2.94 & 0.213 & 0.081 & 38 & 20 \\
October & 7.80 & 2.49 & 0.313 & 0.101 & 74 & 29 \\
November & 6.74 & 2.53 & 0.413 & 0.107 & 86 & 40 \\
December & 7.00 & 2.32 & 0.512 & 0.108 & 113 & 48 \\
\hline
\end{tabular}

The numerical model requires as input a synthetic rainfall series, long enough to allow long-term evaluations for the response of vegetation in a river basin. For this purpose, two synthetic series of 100 years have been generated; one for each considered scheme (A and B), following the procedure described in Sect. 2.1 and using $\alpha$ and $\lambda$ parameters shown in Table 4.

It is important to point out that the two different generated rainfall series present the same mean value, with regard to the seasonal rainfall relative to the growing and the dormant seasons; but this aspect does not warrant also a correspondence year by year of the seasonal rainfall.

\subsection{Model application to Eleuterio}

For the Eleuterio river basin, a time step, $\Delta t$, equal to four hours has been chosen, according to the concepts expressed in Sect. 2.2 (cf. Fig. 2).

Starting from an initial condition of soil moisture equal to the field capacity and solving the Eq. (2), the soil moisture time-profile can be calculated for all the three considered soil-types.

For the computation step by step of the static water stress, Eq. (3) has been used with the exponent $q$ equal to 3, assuming a strongly non-linear relationship between water stress and soil moisture. In this way two static water stress time profiles, using the proposed schemes, has been obtained.
Table 5. Monthly and seasonal values of $E T_{\max }$ for woody vegetation within the Eleuterio river basin (GS = growing season; DS = dormant season).

\begin{tabular}{lc}
\hline Month & $\begin{array}{c}E T_{\max } \\
\mathrm{mm} / \text { day }\end{array}$ \\
\hline Januauy & 1.67 \\
February & 1.91 \\
March & 2.23 \\
April & 3.06 \\
May & 4.13 \\
June & 5.19 \\
July & 5.84 \\
August & 5.79 \\
September & 4.82 \\
October & 3.59 \\
November & 2.50 \\
December & 1.86 \\
\hline Season & $E T_{\max }$ \\
& $\mathrm{mm} /$ day \\
\hline GS & 4.64 \\
DS & 2.03 \\
\hline
\end{tabular}


(a)
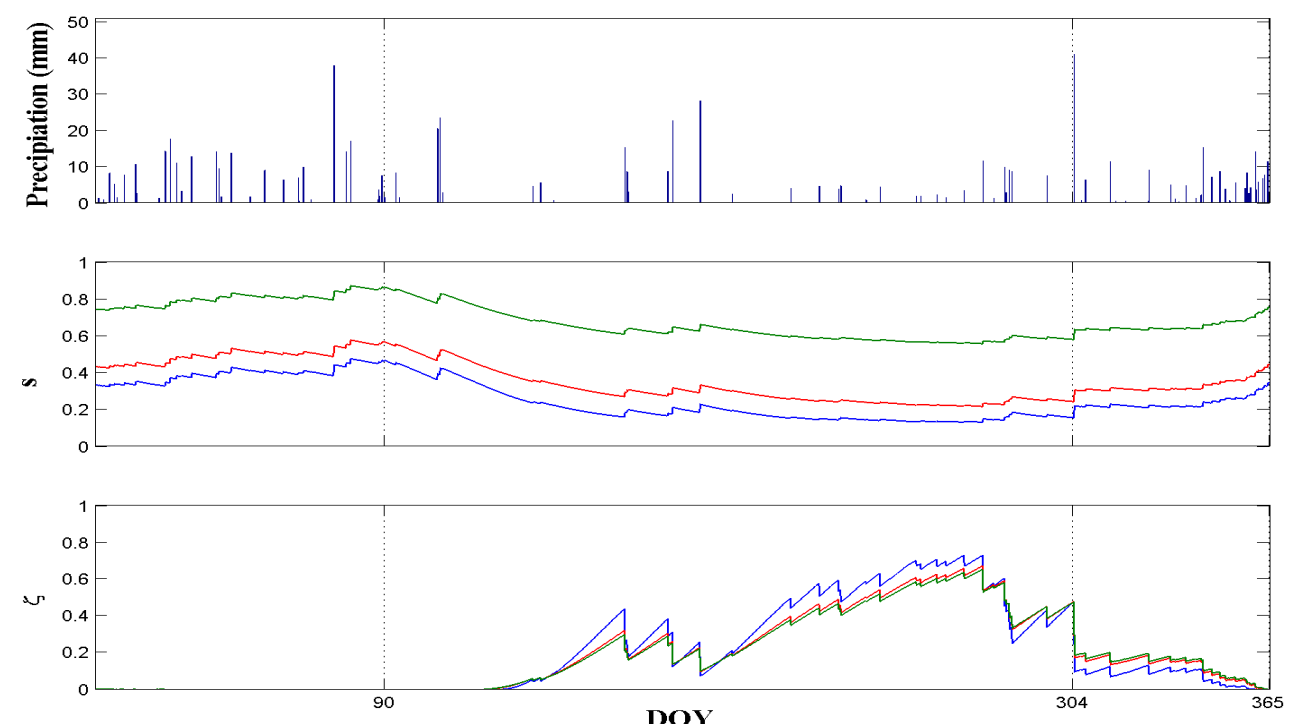

(b)
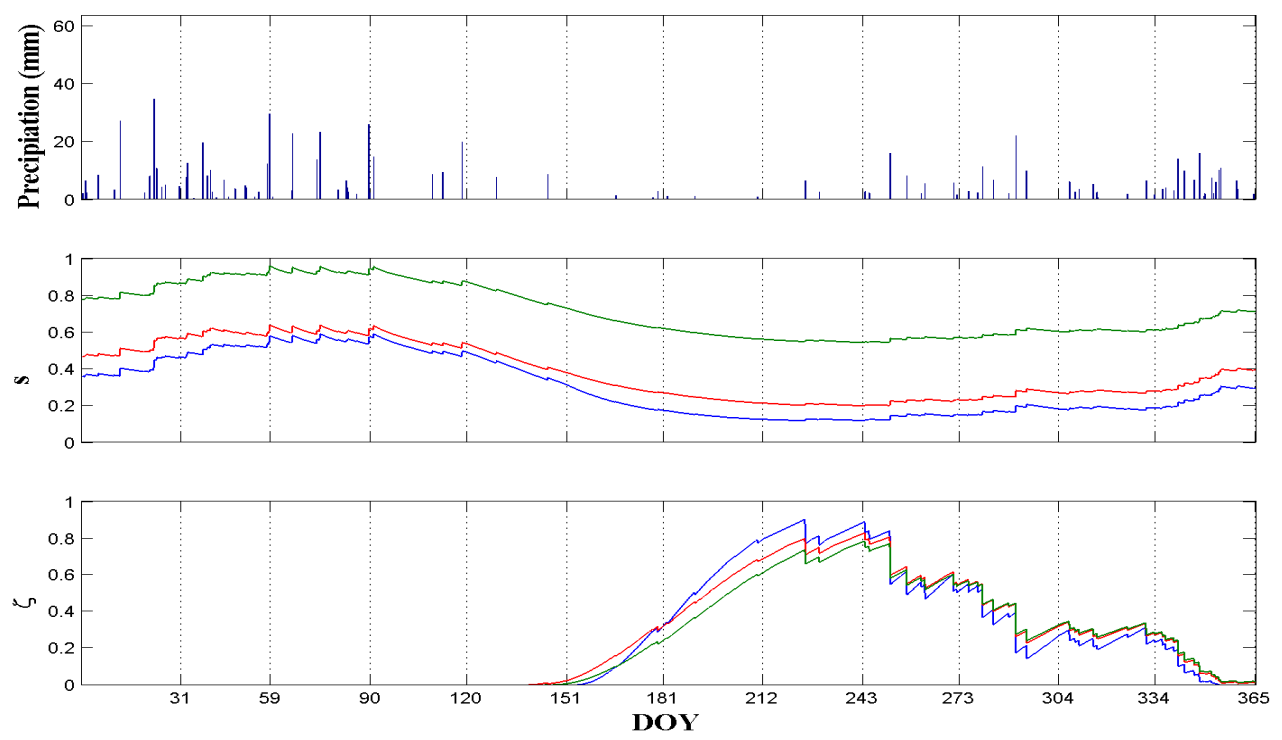

Fig. 7. Time-profiles for two generic representative years. The year relative to SCHEME A (a) and that relative to SCHEME B (b) present the same total values of precipitation during the G.S. $(242 \mathrm{~mm})$ and during the D.S. $(560 \mathrm{~mm})$. Vegetation type: tree. Soil-type: loamy sand (blue), sandy loam (red) and clay (green). On the top the precipitation series, in the middle the soil moisture time-profile and at bottom the static water stress time-profile. DOY = day of year.

Some of the results of simulations carried out using the two schemes are summarized in Fig. 7a and b. Both this plots show the soil moisture time-profile (middle panel) and the static water stress (bottom panel), in response to the synthetic rainfall series (top panel). These figures represent the results relative to two representative years extracted from the two series generated using SCHEME A and B. These years have been chosen by ensuring that they have the same total values of precipitation during the growing season and during the dormant season in both the two schemes (equal to $242 \mathrm{~mm}$ and $560 \mathrm{~mm}$ respectively). The aim of the compari- son between the two figures is to emphasize, in a qualitative manner, the different behaviors of the soil moisture and the consequent trees response, arising from two different climate variability assumed. Analyzing Fig. 7, it is possible to note some of the peculiarities of the two proposed schemes. In the SCHEME B, because of its higher discretization, the rainfall input, the soil moisture and the water stress time profiles are more regular, with less abrupt variations in the temporal evolution (mainly as regards the passage from a season to the other). 
Table 6. Eleuterio river basin. Mean values during the growing season of soil moisture $<s>$, seasonal number of stress periods $n_{s^{*}}$ and its duration $T_{s^{*}}$, static water stress $\left\langle\zeta>\right.$ and static water stress modified $\left\langle\zeta^{\prime}>\right.$, and dynamic water stress $\left\langle\theta>\right.$. Woody vegetation. $s^{*}$ is the soil moisture relative to the incipient stomatal clousure (for each possible soil type).

\begin{tabular}{ccccccc}
\hline Soil Type: & \multicolumn{2}{c}{ Loamy sand $\left(s^{*}=0.31\right)$} & \multicolumn{2}{c}{ Sandy loam $\left(s^{*}=0.46\right)$} & \multicolumn{2}{c}{ Clay $\left(s^{*}=0.78\right)$} \\
\hline SCHEME: & Scheme A & Scheme B & Scheme A & Scheme B & Scheme A & Scheme B \\
\hline$<s>$ & 0.22 & 0.24 & 0.31 & 0.32 & 0.65 & 0.66 \\
$n_{s^{*}}$ & 1.31 & 1.19 & 1.29 & 1.39 & 1.36 & 1.30 \\
$T_{s^{*}}[$ days] & 136.2 & 130.8 & 149.6 & 124.2 & 139.6 & 129.1 \\
$<\zeta>$ & 0.29 & 0.35 & 0.27 & 0.34 & 0.25 & 0.31 \\
$<\zeta^{\prime}>$ & 0.35 & 0.48 & 0.30 & 0.42 & 0.29 & 0.40 \\
$<\theta>$ & 0.37 & 0.45 & 0.35 & 0.41 & 0.32 & 0.39 \\
\hline
\end{tabular}

With a two seasons discretization (SCHEME A) the static water stress appears early in the growing season and continue increasing until the end of the season. Using the twelve months discretization (SCHEME B), the static water stress arrives later and increases more rapidly than the previous scheme, reaching a maximum in August and then decreases because of the higher rain contributions during September and October. The comparison between the maximum values of static water stress reached with the two schemes shows that the SCHEME B gives the highest values. In conclusion the SCHEME A leads to less intensive but more protracted periods of water stress during the growing season.

Afterwards, the analysis has been only focused on the growing season for both the considered schemes. The final results, concerning the 100 years time series, show that the SCHEME B, gives values of the mean soil moisture during the growing season higher than SCHEME A (about 10\% for loamy sand, $3 \%$ for sandy loam and $2 \%$ for clay, cf. Table 6). In fact, using the SCHEME B, two different periods are observable during each simulated year. During the first, at the beginning of the growing season, this scheme simulates lower water losses (evapotranspiration lower than SCHEME A, cf. Fig. 6b) and, at the same time, the rainfall events, which are more frequent, keep the soil moisture higher than the SCHEME A. The second period presents two different behaviors. During the first driest months (from June to August), the evapotranspiration losses are much higher than the ones calculated with the SCHEME A, but they are concentrated and bounded in a shorter period. During the last months, the soil moisture tends to grow again until the end of the season because of the rainfall contribution increase (cf. Fig. 6a) as well as the contemporaneous reduction of evapotranspiration rate in October (cf. Fig. 6b). All that, in conclusion, leads to a higher mean soil moisture during the entire growing season using the SCHEME B than the same value calculated by the SCHEME A.

Using a numerical approach, the mean number of periods with water stress during the growing season, and theirs mean duration can be assessed for each simulated growing season.
Averaging on the whole considered period (100 years), it is possible to obtain the long-term seasonal values of the mean number of downcrossing $n_{s^{*}}$ and theirs mean duration $T_{s^{*}}$ which allow the estimation of the dynamic water stress. Finally, using the Eq. (5), with $r=0.5$ and $k=0.7$ for the woody vegetation (Caylor et al., 2005), the dynamic water stress representative of plant condition within the Eleuterio basin can be obtained for both the proposed schemes.

Even if for the SCHEME B the mean soil moisture during the growing season is higher than the one obtained by the SCHEME A, also the mean static water stress calculated with the former results higher than the one provided by the latter (19\% for loamy sand, $24 \%$ for sandy loam and $23 \%$ for clay). This fact, which is apparently contradictory, is mainly due to the short stress periods with very high values of plant stress in SCHEME B. The same considerations are also valid for the mean static water stress modified, which is more sensitive to the prolonged and intense stress periods. In fact, the differences between the results arising from the two schemes are on the order of $36 \%$ for loamy sand, $38 \%$ for sandy loam and $39 \%$ for clay. As direct consequence, also the dynamic water stress index for the SCHEME B is slightly higher than that obtained using the SCHEME A (22\% for loamy sand, $17 \%$ for sandy loam and $21 \%$ for clay).

Comparing the results of the three different soils it is possible to point out that the woody vegetation suffers less water stress in a clayey soil than that in the other considered soil types, because clayey soil has higher water storage capacity and moreover retains for a longer period the initial moisture during the growing season (Table 6).

In conclusion, even if the differences between the results obtained with the two proposed schemes are minimal with regard to the evaluation of the mean values of soil moisture during the growing season, these differences seems to be more relevant with regard to the evaluation of vegetation response.

In order to give a comparison between the results provided from the analytical solution in stationary condition and from the proposed numerical models, the soil moisture $p d f$ 's during the growing season have been compared for different soil 

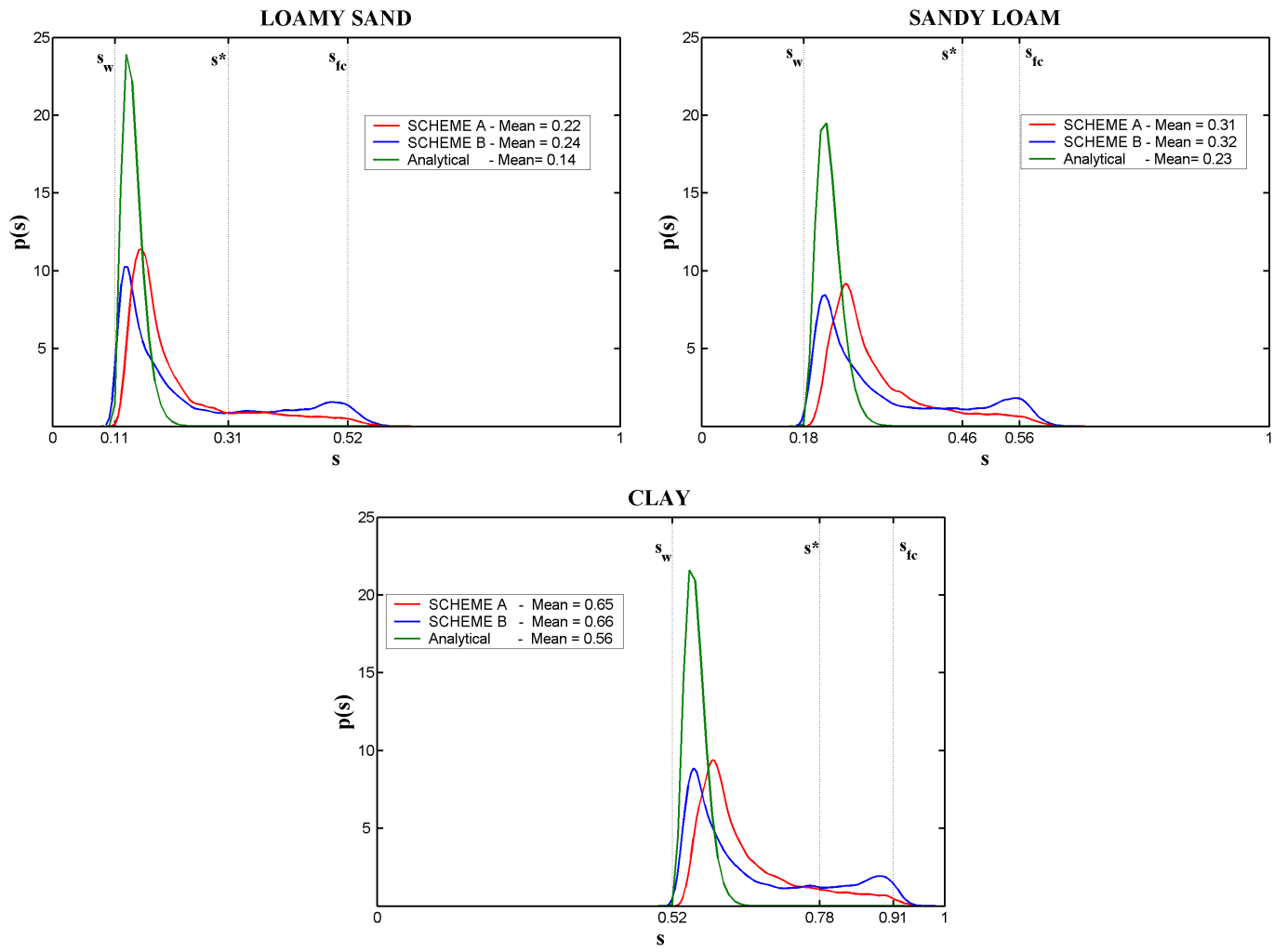

Fig. 8. Eleuterio river basin. Probability density functions of soil moisture during the growing season relative to the analytical solution (green), and to the numerical solutions for the SCHEME A (red) and for the SCHEME B (blue). Vegetation type: tree; Soil-type: loamy sand (top left), sandy loam (top right) and clay (at bottom). In the box of each plot there are the mean values of soil moisture during the growing season.

characteristics. Figure 8 shows that the analytical $p d f$ is unimodal and symmetric, with low variance, whereas the numerical $p d f$ 's show a greater dispersion of the values around the mode and an asymmetric behavior; this is due to the fact that the proposed model takes into account the transient effects of soil moisture at the beginning of the growing season. For this reason, the resulting mean values during the growing season for both the numerical soil moisture $p d f$ 's are consistently higher than that relative to analytical $p d f$.

The transient effect manifests itself in two different ways for the two annual discretization considered. The SCHEME $\mathrm{B}$ leads to a bimodal $p d f$. The right-mode accounts for the transient period and is justified by the high value of soil moisture at the beginning of the growing season but also from the rainfall input assumed in the April-May period, that are higher than the mean seasonal value used in SCHEME A. The left-mode instead takes into account the soil moisture dynamics after the end of the transient period, when a stationary condition could be reached; actually it is very close to the analytical mode, even if it obviously presents a lower probability. In the SCHEME A, the winter soil water recharge is the same as the previous scheme (SCHEME B) but, because of the lower contribution of the rainfall during the first months of the season, the resulting $p d f$ has lower probability in correspondence of high values of soil moisture. Conversely, because of the higher rain input in the July - August period, the unique mode of the $p d f$ resulting from the SCHEME A is higher than the left-mode obtained with the SCHEME B, and it also presents an higher probability for all the three soil types. The SCHEME A works with the same climatic input data used in the analytical formulation (namely with the mean seasonal values of $\alpha, \lambda$ and $E T_{\max }$ during the growing season) and then the differences between the $p d f$ 's derived using these two different approaches, are exclusively due to the effects of the winter recharge of moisture into the soil before the growing season.

\section{Concluding remarks}

The soil moisture dynamics and the vegetation water stress in Mediterranean climate, where the wet and the growing season are out of phase, have been here investigated proposing a numerical ecohydrological model which takes into account the seasonality of the rainfall and of the evapotranspiration demand. Working on the entire year, the model is able to reproduce the winter process of water recharge into the soil, 
which gives the soil moisture condition at the beginning of the growing season, leading to transient effects during the same season. Particular attention has been focused on woody vegetation cover (deep soil) because it is the most critical with regard to the effects on soil moisture dynamics due to a transient period. The proposed model solves the soil water balance, through a finite difference method, working with a temporal step short enough to give a satisfactory approximation of the water losses. Sampling the soil moisture values in the growing season, it is possible to estimate the soil moisture $p d f$, which implicitly considers the transient effects. Through an application to the watershed of Eleuterio and for three different soil types, the numerical $p d f$ 's have been compared with those analytically obtained, showing important differences. The numerical $p d f$ 's are not symmetric and spread over a wide range, from the field capacity, which is a likely value at the beginning of the growing season, to the stomata closure point, which is the most likely value during the growing season (when a steady state condition can be considered reached). The numerical approach allows to take into account the transient effects and consequently gives values of the mean soil moisture during the growing season higher than the values obtained using the analytical approach; in particular this is evident from the comparison between the $p d f$ 's arising from the analytical model and the numerical model with a bi-seasonal annual discretization (SCHEME A). This higher value of the mean soil moisture during the growing season, often warrants the survival of woody species and theirs presence in Mediterranean areas, otherwise impossible to explain by the analytical approach, that would leads to a too high water stress.

The higher is the annual discretization considered for rainfall and evapotranspiration parameters, the more physically consistent is supposed to be the annual soil moisture behavior and then the resulting $p d f$. For this reason, the influence of the description of the annual climate variability on the soil moisture $p d f$ has been also analyzed. Considering a monthly climate variability (SCHEME B) the numerical approach leads to a bimodal soil moisture $p d f$. The behavior of the $p d f$ arising from this type of schematization shows as in a Mediterranean area, there are two different periods during the growing season: the former is characterized by high values of soil moisture due to both the winter water recharge into the soil and the persistence of high precipitations and low water losses from the soil, while the latter, characterized by lower values of precipitations and higher water losses, is not dependent on soil moisture state at the beginning of the growing season and it could be considered as a steady period. The shape of the soil moisture $p d f$ relative to SCHEME B appears hence as the result of an overlap of a typical analytical $p d f$ in steady state condition and a more disperse non-steady $p d f$ relative to the transient period.

In order to evaluate the plant response to the soil moisture dynamics, a new methodology has been proposed. Following the proposed procedure, the mean static and the dynamic wa- ter stress indexes can be numerically computed since the soil water balance equation has been solved and the soil moisture time-profile has been obtained. Also the water stress evaluation is influenced by the description of the annual climate variability. The results arising from the application to the Eleuterio watershed, show that the higher is the annual discretization, the higher are all the indexes of the vegetation water stress, and in particular with regard to the static water stress modified. The substantial difference between the two considered schematizations is that the SCHEME B simulates shorter stress periods with more intensive static water stress.

The numerical evaluation of the dynamic water stress is a new definition of water stress and leads to different results from the analytical estimate, allowing to consider a nonsteady condition for the soil moisture dynamics, and thus to calculate the vegetation water stress in Mediterranean climate, where the presence of a transient period is crucial especially for deep root vegetation.

Edited by: S. Manfreda

\section{References}

Augi, S.: Deduzione di serie temporali di contenuto e di stress idrico da un modello stocastico di bilancio idrologico, Università degli Studi di Palermo (Dottorato di Ricerca in Idronomia Ambientale, XV ciclo, Tesi per il conseguimento del titolo), 2003.

Baldocchi, D. D., Xu, L., and Kiang, N.: How plant functionaltype, weather, seasonal drought, and soil physical properties alter water and energy fluxes of an oak-grass savanna and an annual grassland, Agr. Forest Meteorol., 123, 13-39, 2004.

Caylor, K. K., Manfreda, S., and Rodriguez-Iturbe, I.: On the coupled geomorphological and ecohydrological organization of river basins, Adv. Water Resour., 28, 69-89, 2005.

Kiang, N.: Savannas and seasonal drought: the landscape-leaf connection through optimal stomatal control, Ph.D. thesis, University of California, Berkley, 2002.

Laio, F., Porporato, A., Fernandez-Illescas, C. P., and RodriguezIturbe, I.: Plants in water-controlled ecosystems: active role in hydrologic processes and response to water stress - IV, Discussion of real cases, Adv. Water Resour., 24, 745-762, 2001a.

Laio, F., Porporato, A., Ridolfi, L., and Rodriguez-Iturbe, I.: Plants in water-controlled ecosystems: active role in hydrological processes and response to water stress, II, Probabilistic soil moisture dynamics, Adv.Water Resour., 24(7) 707-723, $2001 \mathrm{~b}$.

Laio, F., Ridolfi, L., Rodriguez-Iturbe, I., and Porporato, A.: Intensive or extensive use of soil moisture: plant strategies to cope with stochastic water availability, Geophys. Res. Lett., 28, 23, 4495-4497, 2001c.

Liguori, V., Raimondi, S., Dazzi, C., and Cirrito, V.: Modello di studio integrato del territorio (Ficuzza-Palermo), Estratto da Quaderni di Agronomia, n.10, Istituto di Agronomia Generale e Coltivazioni Erbacee dell'Università degli Studi di Palermo, 1983.

Manfreda, S., Fiorentino, M., and Iacobellis, V.: DREAM: a distributed model for runoff, evapotranspiration, and antecedent soil 
moisture simulation, Adv. Geosci., 2, 31-39, 2005, http://www.adv-geosci.net/2/31/2005/.

Porporato, A., Laio, F., Ridolfi, L., and Rodriguez-Iturbe, I.: Plants in water-controlled ecosystems: active role in hydrologic processes and response to water stress, III, Vegetation water stress, Adv. Water Resour., 24, 725-744, 2001.

Rodriguez-Iturbe, I., Porporato, A., Ridolfi, L., Isham, V., and Cox, D. R.: Probabilistic modelling of water balance at a point: the role of climate, soil and vegetation, P. Roy. Soc. Lond. A. Mat., 455, 3789-3805, 1999a.

Rodriguez-Iturbe, I., D’Odorico, P., Porporato, A., and Ridolfi, L.: On the spatial and temporal links between vegetation, climate, and soil moisture, Water Resour. Res., 35, 3709-3723, 1999 b.
Rodriguez-Iturbe, I.: Ecohydrology: A hydrologic perspective of climate-soil-vegetation dynamics, Water Resour. Res., 36, 3-9, 2000.

Rodriguez-Iturbe, I., Porporato, A., Laio, F., and Ridolfi, L.: Intensive or extensive use of soil moisture: plant strategies to cope with stochastic water availability, Geophys. Res. Lett., 28, 44954497, 2001.

Rodriguez-Iturbe, I. and Porporato, A.: Ecohydrology of WaterControlled Ecosystems, Cambridge University Press, 2004. 